\title{
$\$$ Research Square

\section{Genome Characterization of the Novel Lytic Genome Sequence of Phage YUEEL01 of the Myoviridae Family}

Gurusamy Raman ( $\sim$ bioramg@gmail.com )

Yeungnam University https://orcid.org/0000-0003-3956-4244

Ayyaru Sivasankaran

Yeungnam University

SeonJoo Park

Yeungnam University

Young-Ho Ahn

Yeungnam University https://orcid.org/0000-0002-8301-5886

\section{Research Article}

Keywords: Enterobacteria phage, Multi-drug resistance, Genome YUEEL01, Phage therapy, Comparative genomics, Homing endonuclease, nrdB and nrdD introns

Posted Date: July 26th, 2021

DOl: https://doi.org/10.21203/rs.3.rs-734852/v1

License: (9) This work is licensed under a Creative Commons Attribution 4.0 International License.

Read Full License

Version of Record: A version of this preprint was published at Virus Research on December 1st, 2021. See the published version at https://doi.org/10.1016/j.virusres.2021.198670. 


\section{Abstract}

Antimicrobial resistance is a global concern due to its rapid emergence in the environment and the associated high risk to human and animal health. Municipal wastewater, including urban, hospital, and pharmaceutical effluent, is the main source of antibiotic and antibiotic resistant bacteria (ARB) contamination, and biological processes are commonly used for wastewater treatment. Biologically based strategies seem to be a promising approach to effective integrated ARB control since they can focus on the bases of antibiotic resistance. To develop an effective bacteriophage against multi-drug resistance (MDR) microbes in municipal wastewater, phage YUEEL01 was isolated from a livestock farm, and its genome sequenced. Phenotypic characterization suggested that the phage is a member of the Myoviridae family, and that it encodes 168,266 bp with an overall GC content of $35.4 \%$ had 259 putative protein-coding genes, 11 tRNA and six hypothetical genes. A number of putative DNA replication and regulation, DNA packing and structure and host lysis genes were identified. Further, whole genome phylogenetic analysis demonstrated that phage YUEEL01 is closely related to phage slur03. Elucidation of the YUEEL01 phage might be helpful when developing antibacterial tools for controlling MDR bacteria in wastewater treatment systems.

\section{Introduction}

Most bacteria are resistant to certain antibiotics, and they can acquire resistance to antibiotics via mutations in chromosomal genes or by horizontal gene transfer [4]. Antibiotic-resistant bacteria (ARB) can occur in several areas including municipal sewers and farm soil fertilized with manure or sewage sludge [1]. In addition to antibiotics being present in wastewater, they may also have long-term permanence in water systems. Genetic selection pressures on micro-organisms at sub-inhibitory concentrations can result in the development of ARB and antibiotic resistant genes $[5,17,18]$.

Wastewater comprises high levels of organic and inorganic matter, as well as high concentrations of microorganisms that can convert sewage into an ecological niche that is especially adapted to the growth and spread of ARB. Recent studies suggest that there is a high level of multidrug-resistant (MDR) bacteria present in wastewater effluent $[18,24,29]$. Bacteriophages are viruses that contain a long, contractile, proteinaceous tail that enables specific host recognition and subsequent adsorption to a receptor at the surface of the host bacterium [13]. Recent studies have reported on bacteriophage applications in various fields including medicine [11], diabetic wound infections (foot ulcers), topical cleaning and disinfection [7], foodborne pathogen control and detection [3, 8, 12, 23, 28], plant diseases [15], water-well clog prevention [10], foam formation reduction [31], and slime and biofilm control [2]. Based on the potential use of phages as antibacterial tools, it can be proposed that during wastewater treatment, inoculation of wastewater with specific lytic phages active against specific bacteria will be effective. To develop a specific lytic phage application for the control of ARB bacteria during wastewater treatment, it is first necessary to understand the genomic features of that phage. 
In the present study, a newly identified phage named YUEEL01 was isolated and characterized. The phage genome was sequenced and annotated and phylogenetic analysis showed that YUEEL01 is belongs to the member of Myoviridae family. These results might be helpful to understand the interaction of phage with their bacterial hosts.

A Gram-negative bacterial isolate, ART2, was isolated from a local municipal wastewater sample in South Korea and used as a source of lytic phages. Briefly, the bacterial mixture was first sequentially filtered through 0.45 and $0.2 \mathrm{~mm}$ filter papers to remove bacteria and other debris in order to isolate phage-like particles. The filtrate containing the phage-like particles was then mixed with soft TSB agar, applied on an agar plate containing a bacterial lawn, and incubated overnight at $37^{\circ} \mathrm{C}$. The plaque that had formed on the plate was gently picked and the bacteria lawn again infected with the phage particles. Eventually, the lytic phage was stored in salt magnesium gelatin (SMG) buffer until further use.

Genomic DNA was extracted by following a standard method [19]. The obtained high-quality DNA was sequenced by using an Illumina NextSeq 500 (LabGenomics, South Korea). The genome sequence of phage YUEEL 01 was assembled by applying a de nova method using a SSAKE assembler (. A total of $6,099,132$ paired-end reads with $1,835,838,732$ total bases $(84.98 \%,>Q 30)$ were generated with a read length of $\sim 300$ bp by using Illumina MiSeq (LabGenomics, South Korea). Sequence trimming, assembly were performed with SSAKE assembler v4.0 [32]. The resulting 125 contigs (>350 bp) were scaffolded with SSAKE using pair-end library reads. Further, assembly gaps and polishing were carried with Racon v1.4.20 (https://github.com/lbcb-sci/racon). In addition, the complete genome (Supplementary Fig. 1) and boundary regions (Supplementary Fig. 2) were mapped using the Bowtie2 v2.4.4 [21] to accomplish the genome is circular or not. The average depth coverage of the assembled sequence is $10,319 x$. The resulting consensus sequence was annaotated using RAST server v2.0 [25] and deposited in the GenBank database under accession number KY2900975.

The phage genome of YUEEL01 is a circular molecule, that contains 168, 266 bp in length with a G+C content of $35.4 \%$. Approximately 277 open reading frames (ORFs) were predicted by RAST server v2.0 [25]. The YUEEL01 genome contains 266 protein-coding genes and 11 tRNAs (tRNA ${ }^{A r g}$, tRNA ${ }^{\text {Asn }}$, tRNA ${ }^{\text {Gln }}$, tRNA ${ }^{\text {Gly }}$, tRNA $^{\text {His }}$, tRNA ${ }^{\text {Leu }}$, tRNA $^{\text {Met }}$, tRNA ${ }^{\text {Pro }}$, tRNA $^{\text {Ser }}$, tRNA ${ }^{\text {Thr }}$ and tRNA ${ }^{\text {Tyr }}$ (Supplementary Table S1). Approximately $64.75 \%$ of the protein-coding genes are located on the plus strand with the remaining $35.25 \%$ protein-coding genes present on the minus strand. The capsid and tail genes, as well as representatives of the DNA replication, packaging, and lysis protein-coding genes, were also identified in the genome of YUEEL01 (Fig. 1).

The phage YUEEL01 genome can be divided into three functional modules, including a phage structure and DNA packaging module, a DNA replication/recombination module, and a host lysis module.

The YUEEL01 genome encodes at least 83 genes associated with nucleotide metabolism. These include DNA polymerase, DNA repair mechanism, DNA helicase, restriction endonuclease activity, replicative helicase-primase, single strand DNA-binding protein-coding, sigma factor for transcription, ribonuclease 
H, DNA topoisomerase, DNA ligase, 3' phosphatase-5'-polynucleotide kinase, adenine-specific methyltransferase, dihydrofolate reductase, and endoribonuclease translational repressor and recombination-related genes. When compared with other closely related phage genomes, most of the genes in those genomes are present in the YUEEL01 genome.

The YUEEL01 genome also encodes at least 18 cell-lysis cassette genes such as holins, spanin Rz, and other phage-encoded proteins. The lysis-related genes were located in the upstream region of DNA metabolism genes. Lyase and hydrolase phage-encoding genes, which are responsible for degradation of carbohydrate-containing polymers on the surface of bacterial cells, are also present in the genome. Due to the high specificity to host receptors by phage particles, these proteins might be useful in medical, food, plant, and animal industries. Previous studies have reported that lysis cassette genes have been effectively applied as detectors of potential foodborne pathogens in the food industry, as a clinical diagnostic tool in the medical industry, as a natural antibacterial for food product preservation, in animal feeding, and in plant cultivation $[6,9,12,14,20,22,26,27]$.

The YUEEL01 genome encodes 114 structural assembly protein genes and 45 DNA packaging-related genes. These genes include phage head, neck, tail fibers, baseplate, major capsid and capsid assembly protein, head-to tail joining protein. host range protein, DNA maturation protein, DNA packaging protein and different types of internal virion protein genes. Most of these genes are homologous to those in its closely related RB3, RB68, and T4 genomes.

In the present study, phage genomes were selected based on closely related genomes. A molecular phylogenetic tree was constructed to evaluate the phylogenetic relationships of Enterobacteria phages by using a complete 20 phage genome sequences. The genome of Staphylococcus phage $\mathrm{K}$ was set as the outgroup. Genome sequences were aligned by using MAFFT v7.475 [16]. The aligned genome sequences were used to generate a phylogenetic tree. Phylogenetic analysis was conducted based on maximum likelihood (ML) analysis with rapid bootstrapping via the general time-reversible model and gamma model site heterogeneity (GTRGAMMA) nucleotide substitution model, with default parameters, in RAxML v8.2.12 [30]. The bootstrap probability of each branch was calculated by performing 1000 replications. The resulting phylogenetic tree was divided into two clades. Two Salmonella and one Serratia phages formed one clade and the other clade was formed by the Enterobacteria, Shigella and Klebsiella phages. Interestingly, Enterobacteria phage dhaeg and Bp7 diverged from the other Enterobacteria phages and formed a sister clade with the Salmonella phages. Also notable was that Serratia phage PS2 and Enterobacteria phage GEC-3S formed a single subclade with the other major Enterobacteria phages with a 100\% BS value. Within this clade, the phage YUEEL01 formed a sister clade with phage slur03 with a $100 \%$ BS value (Fig. 2). Based on morphological and phylogenetic analysis, we deduce that phage YUEEL01 is a novel member of the family Myoviridae.

\section{Nucleotide sequence accession number}

The GenBank accession number for Escherichia phage YUEEL01 is KY2900975 (https://www.ncbi.nlm.nih.gov/nuccore/KY290975). 


\section{Declarations}

\section{Acknowledgments}

This study was supported by the Basic Science Research Program through the National Research Foundation of Korea funded by the Ministry of Education (2020R111A305481611).

\section{Author contributions}

G.R., A.S., S.P., and Y.A., conceived and designed the study. Y.A. provided the materials. S.P. and Y.A. supervised the work and critically revised the manuscript. A.S performed the isolation as well as the phenotypic characterization of the phage. G.R performed the bioinformatic analysis, the genome annotations, analyzed the data, and drafted the manuscript.

\section{Competing interests}

The authors read and approved the manuscript and declare no competing financial interests.

\section{References}

1. Amador PP, Fernandes RM, Prudencio MC, Barreto MP, Duarte IM (2015) Antibiotic resistance in wastewater: occurrence and fate of Enterobacteriaceae producers of class $A$ and class $C$ betalactamases. J Environ Sci Health A Tox Hazard Subst Environ Eng 50:26-39

2. Araki M (1986) Advanced slime control process with bacteriophages. Kogyo Yosui 332:25-30

3. Atterbury RJ, Van Bergen MA, Ortiz F, Lovell MA, Harris JA, De Boer A, Wagenaar JA, Allen VM, Barrow PA (2007) Bacteriophage therapy to reduce salmonella colonization of broiler chickens. Appl Environ Microbiol 73:4543-4549

4. Blair JM, Webber MA, Baylay AJ, Ogbolu DO, Piddock LJ (2015) Molecular mechanisms of antibiotic resistance. Nat Rev Microbiol 13:42-51

5. Bouki C, Venieri D, Diamadopoulos E (2013) Detection and fate of antibiotic resistant bacteria in wastewater treatment plants: a review. Ecotoxicol Environ Saf 91:1-9

6. Courchesne NM, Parisien A, Lan CQ (2009) Production and application of bacteriophage and bacteriophage-encoded lysins. Recent Pat Biotechnol 3:37-45

7. Curtin JJ, Donlan RM (2006) Using bacteriophages to reduce formation of catheter-associated biofilms by Staphylococcus epidermidis. Antimicrob Agents Chemother 50:1268-1275

8. Donovan DM (2007) Bacteriophage and peptidoglycan degrading enzymes with antimicrobial applications. Recent Pat Biotechnol 1:113-122

9. Fischetti VA (2008) Bacteriophage lysins as effective antibacterials. Curr Opin Microbiol 11:393-400

10. Gino E (2003) Prevention and rehabilitation of clogged wells by physicochemical and biological treatment as a function of chemical and biological composition of ground water. Technion-Israel Institute of Technology 
11. Gorski JABR, Miedzybrodzki B, Weber-Dabrwoska (2007) Bacteriophages in medicine. In: McGrath S DVS (ed) Bacteriophage. Caister Academic Press, Wymondham, pp 125-158

12. Hagens S, Loessner MJ (2007) Application of bacteriophages for detection and control of foodborne pathogens. Appl Microbiol Biotechnol 76:513-519

13. Hamdi S, Rousseau GM, Labrie SJ, Tremblay DM, Kourda RS, Ben Slama K, Moineau S (2017) Characterization of two polyvalent phages infecting Enterobacteriaceae. Sci Rep 7:40349

14. Hsu CR, Lin TL, Pan YJ, Hsieh PF, Wang JT (2013) Isolation of a bacteriophage specific for a new capsular type of Klebsiella pneumoniae and characterization of its polysaccharide depolymerase. PLoS One 8:e70092

15. Jones JB, Jackson LE, Balogh B, Obradovic A, Iriarte FB, Momol MT (2007) Bacteriophages for plant disease control. Annu Rev Phytopathol 45:245-262

16. Katoh K, Standley DM (2013) MAFFT multiple sequence alignment software version 7: improvements in performance and usability. Mol Biol Evol 30:772-780

17. Kim S, Aga DS (2007) Potential ecological and human health impacts of antibiotics and antibioticresistant bacteria from wastewater treatment plants. J Toxicol Environ Health B Crit Rev 10:559-573

18. Korzeniewska E, Korzeniewska A, Harnisz M (2013) Antibiotic resistant Escherichia coli in hospital and municipal sewage and their emission to the environment. Ecotoxicol Environ Saf 91:96-102

19. Kumar RS, Ayyadurai N, Pandiaraja P, Reddy AV, Venkateswarlu Y, Prakash O, Sakthivel N (2005) Characterization of antifungal metabolite produced by a new strain Pseudomonas aeruginosa PUPa3 that exhibits broad-spectrum antifungal activity and biofertilizing traits. J Appl Microbiol 98:145-154

20. Labrie SJ, Samson JE, Moineau S (2010) Bacteriophage resistance mechanisms. Nat Rev Microbiol 8:317-327

21. Langmead B, Salzberg SL (2012) Fast gapped-read alignment with Bowtie 2. Nat Methods 9:357354

22. Lu TK, Bowers J, Koeris MS (2013) Advancing bacteriophage-based microbial diagnostics with synthetic biology. Trends Biotechnol 31:325-327

23. McKinstry MER (2005) Use of phages in therapy and bacterial detection. In: Waldor MKFD, Sankar Adhya (ed) Phages. American Society for Microbiology, Washington, DC, pp 430-440

24. Moura A, Pereira C, Henriques I, Correia A (2012) Novel gene cassettes and integrons in antibioticresistant bacteria isolated from urban wastewaters. Res Microbiol 163:92-100

25. Overbeek R, Olson R, Pusch GD, Olsen GJ, Davis JJ, Disz T, Edwards RA, Gerdes S, Parrello B, Shukla M, Vonstein V, Wattam AR, Xia FF, Stevens R (2014) The SEED and the Rapid Annotation of microbial genomes using Subsystems Technology (RAST). Nucleic Acids Res 42:D206-D214

26. Schmelcher M, Loessner MJ (2014) Application of bacteriophages for detection of foodborne pathogens. Bacteriophage 4:e28137 
27. Schofield DA, Sharp NJ, Westwater C (2012) Phage-based platforms for the clinical detection of human bacterial pathogens. Bacteriophage 2:105-283

28. Shigenobu MMR, Masayuki K, Hiroshi H, Takako U, Kazue A, Junpei U, Shingo S, Shosuke I (2006) Bacteriophage therapy-a short review. Recent Res Develop Virol 7:1-11

29. Silva JCG, Callejas L, Lopez H, Olmos J (2006) Frequency of transferable multiple antibiotic resistance amongst coliform bacteria isolated from a treated sewage effluent in Antofagasta, Chile. Elect J Biotechnol 9:533-540

30. Stamatakis A (2006) RAxML-VI-HPC: maximum likelihood-based phylogenetic analyses with thousands of taxa and mixed models. Bioinformatics 22:2688-2690

31. Thomas JA, Soddell JA, Kurtboke DI (2002) Fighting foam with phages? Water Sci Technol 46:511518

32. Warren RL, Sutton GG, Jones SJM, Holt RA (2007) Assembling millions of short DNA sequences using SSAKE. Bioinformatics 23:500-501

\section{Figures}




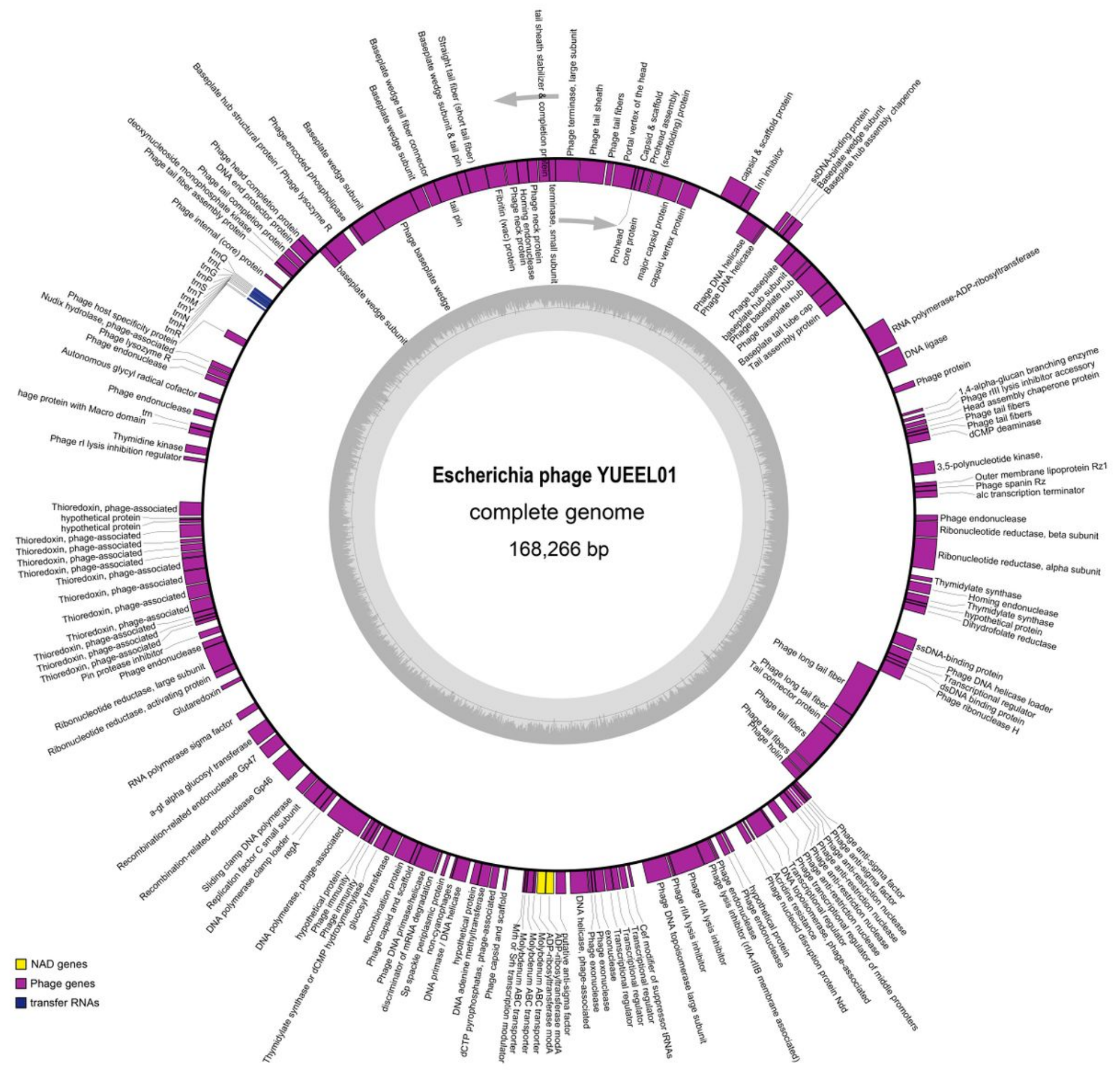

\section{Figure 1}

Gene map of Enterobacteria phage YUEEL01. Genes located on the outside of the outermost layer of the circle are transcribed in a counterclockwise direction, whereas genes located on the inside of the circle are transcribed in a clockwise direction. The colored bars indicate known protein-coding genes and transfer RNA (tRNA) genes. The dashed, darker gray area in the inner circle denotes the guanine-cytosine (GC) content of the genome, whereas the lighter gray area in the inner circle indicates the adenosine-thymine (AT) content of the genome. 


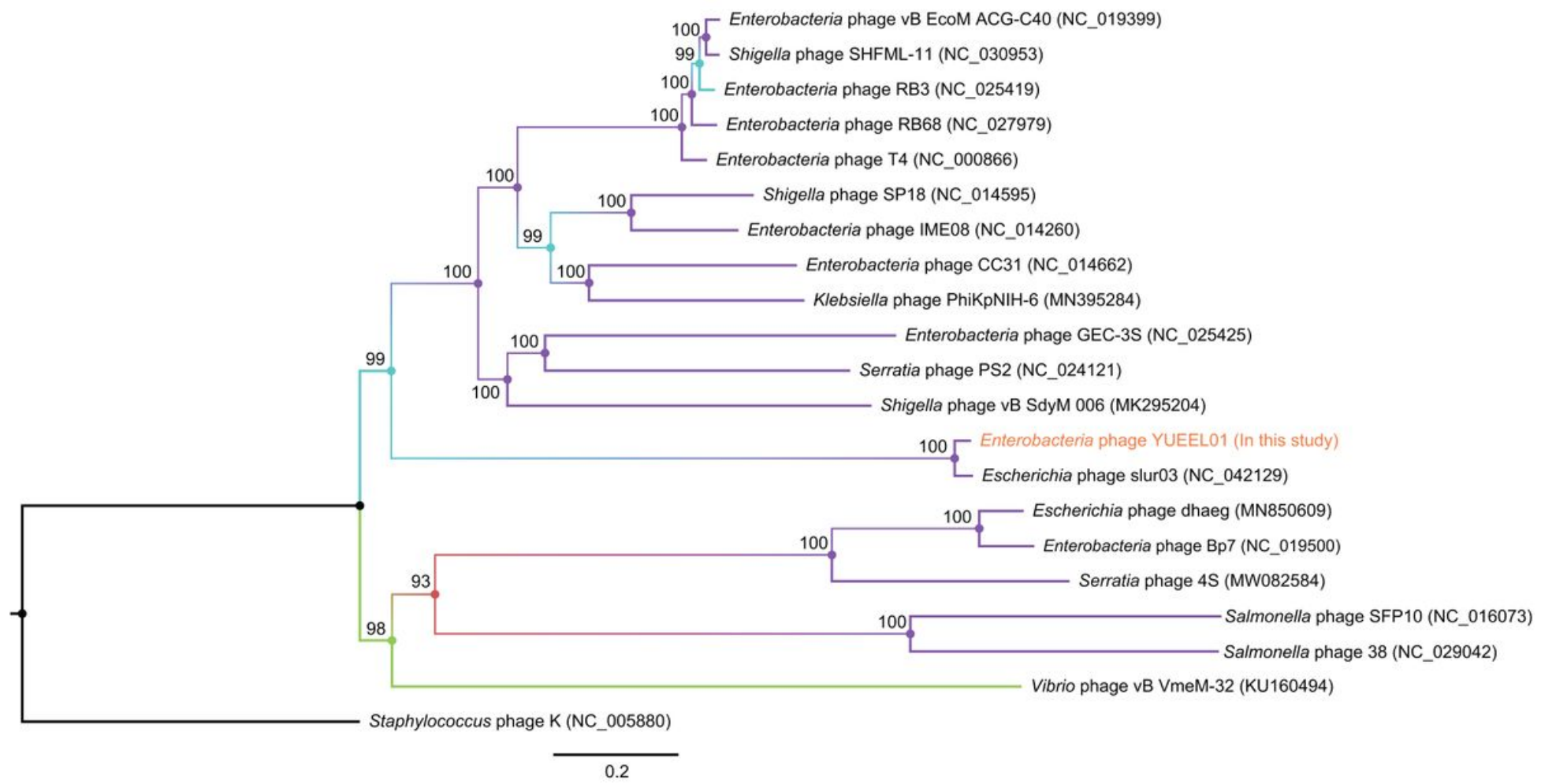

\section{Figure 2}

Molecular phylogenetic analysis of whole genome sequences of the Enterobacteriaceae family. The tree was constructed by performing maximum likelihood (ML) analysis using RaxML software and the GTRGAMMA nucleotide model. The stability of each tree node was tested by undertaking bootstrap analysis with 1000 replicates. Staphylococcus phage K was set as the outgroup. Rectangular red box shows the position of Enterobacteria phage YUEEL01.

\section{Supplementary Files}

This is a list of supplementary files associated with this preprint. Click to download.

- Supplementaryfiles.docx 